\title{
Paradigma estético y artes decorativas en el Chile republicano. Una aproximación a través de las exposiciones de 1873 y $1875^{1}$
}

\section{Aesthetic paradigm and decorative arts in Republican Chile. An approach through the exhibitions of 1873 and 1875}

\author{
Solène Bergot, Enrique Vergara Leyton y Claudio Garrido Peña \\ Universidad Andrés Bello / Pontificia Universidad Católica de Chile / \\ Universidad Diego Portales. Santiago, Chile. \\ solene.bergot@unab.cl / evergaral@uc.cl / claudio.garridop@udp.cl
}

\section{Resumen}

Este artículo reflexiona sobre el cambio de paradigma estético que afecta al entorno material de las elites chilenas en la década de 1870. En este sentido, postula que el desplazamiento de lo colonial a favor de un nuevo "buen gusto", que apela a lo neoclásico y a lo francés, responde al proyecto de nación que las elites proyectan e implementan después de la Independencia, basado en las nociones de modernidad y de progreso. En cuanto a cultura material, este fenómeno se visibiliza en particular en dos espacios: las exposiciones como instancia de mediación y el palacio como espacio de recepción y apropiación.

Palabras clave: exposición, artes decorativas, cultura material, modernidad.

\section{Abstract}

This article reflects on the change in the aesthetic paradigm which affected the material environment of the Chilean elite in the 1870s. In this respect, it suggests that the shift from a colonial culture towards a new culture of "good taste", based on Neoclassical and French style, was in line with the national project planned and implemented by the elites after the Independence, a project based on the concepts of modernity and progress. As for material culture, this phenomenon was evident in two spaces in particular: exhibitions as an instance for intervention and palaces as a place for reception and appropriation.

Keywords: exposition, decorative arts, material culture, modernity.

1 Proyecto Fondecyt 1130457 (Chile), "Elite y visualidad en la Belle Epoque chilena. Artes decorativas y arquitectura como dispositivos de distinción social". 


\section{Introducción}

Siguiendo la línea de Benedict Anderson, que se centra en el estudio de la construcción de un proyecto nacional, civilizado y moderno durante el siglo xIx, este artículo se propone interrogar la relación entre el presente republicano y el pasado colonial en Chile. Bajo esta perspectiva, se toman como puntos de referencia las exposiciones realizadas en Chile en la década de 1870, en particular la Exposición del Coloniaje de 1873 y la Exposición Internacional de Santiago de 1875, y se estudia un grupo de objetos que ha suscitado escaso interés a nivel historiográfico, a saber, las “artes decorativas". En este estudio, se entenderá por artes decorativas todas aquellas "obras que son principalmente utilitarias en forma o función, pero que tienen un valor estético proporcionado por el diseño, la decoración o embellecimiento" (Getty Research Institute). ${ }^{1}$ De esta forma, nuestro análisis se enfoca en la relación entre las elites chilenas ${ }^{2}$ y su entorno material; específicamente, postulamos que en la década de 1870 se produjo un cambio en el paradigma estético en relación con el proyecto republicano que las elites chilenas buscaron asentar a nivel político, después de la Independencia ocurrida en 1818. De esta forma, se transita desde lo "colonial", entendido como herencia de un pasado mestizo y local asociado a la barbarie (Bauer 156), hacia lo neoclásico en arquitectura y los estilos franceses en lo ornamental. Este proyecto se legitimó desde las ideas de modernidad y de progreso, y así lo entendieron los visitantes de las exposiciones, como se puede apreciar en una reseña de 1875 que señala la voluntad de "presentar al lector, bajo un golpe de vista rápido a la par que comprensivo, lo que nuestra Esposición tiene de bello, de útil i de aplicable al fomento de los diversos intereses del progreso nacional" (Letelier 4).

Este entorno material renovado se presenta en un doble ámbito, ya que, por una parte, se trata de un entorno proyectado en las Exposiciones, y por otra, es "vivido" en los palacios que las elites empiezan a construir desde 1860, particularmente en Santiago. En este sentido, se integrarán a este análisis las propuestas que ponen el acento sobre la cultura material, entendida como el conjunto de objetos y su instalación y valoración social dentro del espectro de lo decorativo. Este concepto, proveniente de la antropología, permite distanciarse de "las jerarquías y del elitismo asociados a

1 La definición agrega que las artes decorativas incluyen "cerámica, muebles, textiles, vidrio, cuero, orfebrería, armas y armaduras, relojes y joyas, y otros de casa o utilitarios". Se distinguen de las Bellas Artes, ya que estas "se considera tradicionalmente que exigían una capacitación más amplia y se limitaron a los medios de la pintura, escultura, dibujo y arquitectura". Si bien se puede relativizar esta distinción entre ambas categorías por un aspecto técnico, se conservarán las categorías que se incluyen en artes decorativas, ya que son operativas en el registro y en el agrupamiento de objetos.

2 En este artículo, se entenderá por elite el "sector social que, ya fuera por su capacidad económica, por su estatus, por su influencia en la vida política o por las funciones públicas que pudiera desempeñar, constituye un estrato que participa de una situación de privilegio en un marco geográfico determinado" (Ponce y Amadori). En el caso específico de Chile, habría que agregar que, según María Rosaria Stabili, las elites se caracterizaron por un universo reducido de apellidos y antepasados que actuaron en favor de la Independencia nacional, además de la posesión de tierras cultivables, como hacienda o fundo. Es importante destacar que son muy pocos los autores que hacen referencia a este caso, sin entrar en mayores detalles sobre su real alcance. 
las artes decorativas, para recalcar la importancia social del objeto usual, ordinario, anónimo" (Hellman 499). Se complementará el análisis de las artes decorativas con los usos y significados dados por la sociedad en la cual se insertaron.

A partir de la revisión de una selección de las fuentes disponibles sobre las exposiciones de 1873 y 1875 (archivos de la organización, catálogos, prensa, reseñas de visitantes, memorias), sobre los palacios (fotografías, planos, memorias) y el levantamiento de material visual asociado a las artes decorativas, planteamos que estas instancias se configuran como un doble espacio de discurso y de exhibición, aspectos que se expresan en la materialidad y en su capacidad transformativa del entorno cultural. ${ }^{3}$ A su vez, esta cultura material rearticuló las dimensiones estética y utilitaria asociadas a la idea de progreso, en tanto se produjo un cambio de los referentes visuales desde lo hispánico-colonial al neoclasicismo arquitectónico y decorativismo francés, en consonancia con los cambios en la vida política nacional. Debemos aclarar que el catálogo de la exposición de 1873 no incluía material visual alguno, mientras que el catálogo oficial de 1875 incluía exclusivamente vistas de la exposición y reproducciones de maquinarias y de obras de arte (esculturas) y el catálogo de la Casa Rose Innes y Ca. presentaba un rango mayor de objetos. Sin embargo, ninguno pertenece a la categoría de artes decorativas. En este sentido, solo contamos con listados de objetos, además de escasas descripciones en la prensa y registros visuales de esta categoría.

Este artículo se ordena en cuatro secciones. En la primera se presenta el contexto general en el que se produce el cambio de paradigma estético que afecta a las artes decorativas, a saber, la conformación y aplicación de un nuevo proyecto nacional basado en la noción de modernidad. La segunda se centra en la Exposición del Coloniaje de 1873 como evento de cierre de lo colonial a nivel visual y material. La tercera analiza la Exposición Internacional de Santiago de 1875 como un medio de difusión de los nuevos patrones del "buen gusto", asociado al neoclásico y a los estilos franceses. Por último, la cuarta sección aborda la instalación del nuevo entorno material promovido por la Exposición de 1875 en el espacio de vida de las elites, esto es, el palacio.

\section{De lo colonial a lo neoclásico: la tensión de lo moderno}

Como señala la historiadora Gertrude M. Yaeger, "de los tres problemas fundamentales de la vida intelectual del siglo xix hispanoamericano: construir identidades nacionales creíbles, explicar el malestar nacional y reconciliarse con el pasado colonial, el último tuvo quizás la máxima importancia" (118). Desde esta perspectiva, las exposiciones decimonónicas chilenas que se venían organizando en Chile desde 1869

3 Cabe señalar que, para los fines del presente artículo, entenderemos por "prensa" la publicación oficial de la exposición de 1875: el Correo de la Exposición. Si bien la prensa nacional se hizo el eco de ambas exposiciones en términos de su organización y de su impacto, las referencias a los objetos expuestos se centraron primordialmente en la agricultura, la maquinaria y las Bellas Artes. Por ende, su aporte en cuanto a artes decorativas es marginal. 
(Exposición Nacional de Agricultura) responden a la construcción discursiva de la nación, en la medida en que realzaban tópicos políticos, económicos y mediáticos que giraban en torno a la modernidad y la civilización, de modo que se constituyeron en instancias de acceso a una dimensión exhibitoria del proyecto nacional. Este proyecto se podía construir rechazando o aceptando el pasado colonial, para expresarse como una narrativa objetual del ideario trazado para el país, ahora disponible para el ciudadano ilustrado. Esta idea estaba presente, entre otros documentos, en el discurso de inauguración de la Exposición de 1875, pronunciado por el presidente del directorio, Rafael Larraín: "En este solemne día un pueblo entero se agolpa en torno de los altares del propio progreso, para contemplar con justa satisfacción lo que ha hecho en medio siglo de trabajo i aprender de naciones más adelantadas lo que aún queda por hacer" (Correo de la Exposición, 16/09/1875, 3). Larraín no se refería explícitamente a lo colonial, pero el hecho de fijar el principio del progreso cincuenta años antes lo hacía coincidir con el principio de la República (1818). En este sentido, la exposición tenía propósitos ideológicos combinados con comerciales - presentar los productos chilenos en distintos mercados-, pedagógicos -educar al pueblo, pensado como los obreros en formación-y posicionales - ubicar a Chile en el mapa de potencias internacionales-.

Las exposiciones fueron acompañadas de una visualidad que manifestaba su retórica exhibitoria en soportes como los boletines de las exposiciones y los catálogos, que podían estar impresos por sección e incluso por expositor. Debido al limitado desarrollo de la prensa y de la imprenta chilena respecto de la reproducción de imágenes, las ilustraciones que se incluían correspondían fundamentalmente a grabados monocromos. ${ }^{4}$ La relevancia de lo visual tiene su explicación en la idea de que el Estado era un agente civilizatorio y pedagógico, propia de la generación de intelectuales de 1842, conformada por José Victorino Lastarria (1817-1888), Miguel Luis Amunátegui (1828-1888), Diego Barros Arana (1830-1907), Domingo Faustino Sarmiento (1811-1888) y Andrés Bello (1781-1865), y que alcanzó expresiones institucionales notables en el gobierno de Manuel Montt (1851-1861) (Stuven 61-94). Paralela a la reflexión del mundo intelectual, se desarrolló una política científica e historiográfica que consideraba la imagen y los objetos como elementos centrales para el conocimiento y la divulgación de la nación. A modo de ejemplo, podemos mencionar el Atlas desarrollado por Claudio Gay (1851), la publicación de la Galería Nacional de Hombres Célebres de Narciso Desmadryl (1854) y, más tarde, la construcción e inauguración del Museo Nacional de Bellas Artes (1880). En este sentido, se deduce que mediante distintas materialidades y aplicaciones de la imagen, la nación se hacía

4 La prensa chilena de la década de 1870 aún no introducía la imagen fotográfica como parte de su propuesta editorial porque, por una parte, no existía todavía este enfoque editorial y, por otra, porque no contaba con la tecnología necesaria para la reproducción de fotografías. Con la creación de El Diario Ilustrado en 1902 recién se introduce la fotografía como parte de la política editorial del periodismo. Para una introducción sobre el desarrollo técnico de la imprenta en el siglo xix chileno, ver Jorge Soto (108-145). 
aprehensible y objetivable para los habitantes del país, una imagen dotada de ideales científicos y de progreso que permitían construir, en su circulación y apropiación, el ideario de la República.

Esta política es fruto de la conjunción entre iniciativa pública y privada y, en este sentido, una de las líneas de trabajo historiográfico sobre las exposiciones internacionales y la conformación de los museos en América Latina del siglo xIx ha mostrado que el desarrollo científico, agrario, industrial y artístico se debió en gran parte a la iniciativa de empresarios y filántropos, apoyado en la creación de entidades públicas destinadas a la formación de nuevos espacios y de nuevos profesionales que debían apoyar este desarrollo, como lo fueron la Quinta Normal de Agricultura en 1841 y la Escuela de Artes y Oficios en 1849 (Robles; Drien; Sanhueza, "El Museo Nacional de Chile"; Murillo).

A su vez, esta política tenía por objetivo conferir una dimensión material al ideario republicano a través de distintas manifestaciones visuales (impresa, escultórica, arquitectónica y paisajista), lo que produjo una tensión permanente entre lo colonial -entendido como herencia de lo monárquico- y lo neoclásico, como expresión de lo republicano y del proyecto moderno. En este sentido, en palabras de Constanza Acuña, "el antiguo orden virreinal fue calificado como un periodo donde primó la ignorancia y la falta de libertad" (7), de modo que lo colonial sufrió un proceso de deslegitimación de parte del sector liberal y fue rechazado por representar "un sistema autoritario, jerárquico y católico" (13). Este cambio de paradigma tuvo su máxima expresión material en la arquitectura y el proyecto de ciudad que se comenzó a instaurar con la intendencia de Benjamín Vicuña Mackenna (1872-1875) en Santiago, que tenía como principal referente la experiencia de lo moderno en Francia, donde la ciudad se constituyó en el escenario para exhibir los logros de la República y la expresión del ciudadano en su habitar cotidiano. Vicuña Mackenna fue también quien promovió la Exposición del Coloniaje de 1873, que constituye el evento que cierra el fenómeno de desvalorización de lo colonial en el siglo xıx. En este sentido, ambas exposiciones pueden haber sido pensadas como un conjunto, cuyo objetivo era generar un contrapunto visual entre lo colonial y el proyecto moderno a nivel del país.

\section{La superación de lo colonial: la Exposición del Coloniaje de 1873}

La Exposición del Coloniaje de 1873 tuvo lugar en el mes de septiembre en Santiago, y fue ideada por su promotor como "una memoria útil y razonada que sirva para estudiar, si es posible, el coloniaje, en lo más adentro de sus entrañas, en lo más denso de sus tinieblas" (Catálogo razonado viI). A pesar de representar un esfuerzo por conocer y no solamente rechazar lo colonial, para Acuña, la instancia "no significaba en ningún caso reivindicar lo que representaba simbólica e ideológicamente ese periodo, sino más bien entender el proceso de transformación del presente a partir de 
una reconstitución documentada y desmitificadora del pasado" (12). En este sentido, su celebración respondería a un intento de cerrar el ciclo colonial y rechazar su estilo, considerado -desde lo material- como inadecuado para el nuevo régimen político chileno. Esta operación se realiza desde una perspectiva ilustrada, es decir, desde el saber y la razón que permiten comparar, para luego proceder a instalar la idea de una nación moderna, en el sentido de nueva, con las exposiciones posteriores.

Si bien fue pensada como una gran manifestación, que incluso se destacó por sus nuevas formas de "museificar" el pasado (Faba, "Agencias inesperadas") 5 y por instaurar una novedosa cultura visual (Faba, "Cultural visual”), la Exposición del Coloniaje no encontró resonancia en su potencial público. Según el secretario de la comisión directiva, Ramón Subercaseaux Vicuña (1854-1937), este desencuentro se debió a "la falta de preparación artística y la de interés por el pasado, que siempre caracteriza a las sociedades nuevas" (227). En este sentido, se criticó lo poco educado de la población, incluso de sus elites, y su escasa inscripción en su propio pasado, lo que se traducía en el descuido hacia lo patrimonial y una mirada puesta únicamente en el futuro. Sin embargo, la falta de público también se podría deber al intento de imponer un discurso y un estilo en una sociedad que, en su mayoría, participó escasamente del debate respecto del valor de lo colonial, pues este debate se dio fundamentalmente en el campo literario-historiográfico de las elites.

Paradojalmente, la Exposición del Coloniaje visibilizó la voluntad de inserción en el relato nacional de dos grupos, sin que se estableciera una jerarquización entre ellos: por una parte, familias que gozaban de un gran prestigio desde la Colonia y, por otra, familias o individuos de ascenso social más reciente, ocurrido poco antes o después de la Independencia. Respecto de los primeros, Subercaseaux escribió que muchos de los objetos presentados "tenían valor no solo arqueológico, sino también artístico", subrayando que "no pocos traían procedencia de mérito histórico comprobado, por haber pertenecido a hombres o familias eminentes de nuestra antigüedad" (227). Esta afirmación se puede efectivamente cotejar en el catálogo de la exposición, el que especificaba la propiedad de los objetos expuestos. Un estudio de estos dueños permite afirmar que pertenecían al ámbito privado, es decir, a los descendientes de las familias de la elite colonial y a las órdenes religiosas. En palabras de Patience Schell, esto se debe a que, "para la elite, la exposición era una muestra pública de sus ancestros ilustres y su riqueza material. Sus muebles y sus pinturas, en ese ambiente, se volvieron tesoros y patrimonio nacionales. Su historia familiar era la historia de la nación de Chile" (100). Para el segundo grupo, en cambio, el préstamo de sus objetos le permitía inscribirse en una tradición de la cual no habían sido participes. Es el caso, entre otros, de los objetos prestados por José Tomás Urmeneta (1808-1878), que apa-

5 En este artículo, Faba postula que en el último tercio del siglo xix se experimentó un proceso de "patrimonialización" y de "museificación" de los objetos coloniales en Chile. Un primer paso de este proceso definido por Faba fue la Exposición del Coloniaje, pues allí se presentaron por primera vez objetos utilitarios, sin su carácter cotidiano para conferirles el valor de objeto histórico. 
recen atribuidos a su esposa, Carmen Quiroga. Si bien los Urmeneta habían llegado a Chile en la segunda mitad del siglo Xviı y se habían insertado en la elite comercial del Norte Chico, no fue hasta la década de 1830 que empezaron a acumular una gran fortuna gracias a las minas de cobre, lo que les permitió integrarse paulatinamente en la vida política y en la elite santiaguina (Nazer). En este sentido, el matrimonio entre Amalia Urmeneta Quiroga (1837-1861) y Maximiano Errázuriz Valdivieso (18321890 ) en 1855, entre otros ejemplos, simbolizó la unión entre un sector empresarial pujante y una elite colonial empobrecida.

Un análisis más detallado de los objetos presentados muestra un cierto desajuste con el criterio curatorial de "Colonia", pues la Colonia debería responder a un marco temporal (de la Conquista española en los territorios americanos al proceso de Independencia de estos configurados en naciones), a uno geográfico (España peninsular y sus colonias en América) y a un estilo particular, a saber, el Barroco de corte europeo y su variante americana, seguido del estilo rococó, considerando también la producción indígena.

Sin embargo, en primer lugar, los objetos presentados desbordaban el marco cronológico estricto de la Colonia, ya que Vicuña Mackenna había propuesto una exposición que llegara hasta 1849, durante el segundo mandato del General Manuel Bulnes (1841-1851), lo que permitía unir el pasado colonial con el casi presente republicano (Acuña 8). En segundo lugar, no solo se componía de originales, sino también de copias y de cuadros pintados especialmente para la exposición. ${ }^{6} \mathrm{Y}$, por último, la muestra integraba objetos producidos fuera del imperio español, por ejemplo, en Francia o Italia e incluso en China y Japón, lo que implicaba un estilo diferente. Ahora bien, si algunos de estos objetos fueron usados por sus dueños durante la Colonia, no era el caso de todos, ya que también aparecen agrupaciones que vienen a conformar colecciones. Es el caso, por ejemplo, de Maximiano Errázuriz Valdivieso, quien prestó 31 piezas en varias secciones (cuadros, estatuas, retablos, muebles, tapicerías, objetos ornamentales), las que fueron adquiridas durante un viaje a Europa entre 1871 y 1872 (Catálogo razonado 73-4). ${ }^{7}$

La Exposición del Coloniaje inicia una transición hacia nuevos patrones. De esta forma, si bien las instancias de transmisión del patrimonio (como las herencias) siguieron incluyendo lo colonial, las nuevas adquisiciones debían orientarse a un paradigma estético diferente, que reflejara el proyecto político-social de las elites republicanas para la nación. Por ende, se debía sustituir un entorno material considerado como una herencia de un sistema político y social obsoleto, incluso oscurantista, por uno

6 Los cuadros pintados especialmente para la Exposición del Coloniaje corresponden a las entradas 1, 3 a 6 y 10 a 12 del Catálogo razonado.... Fueron encargados a artistas chilenos (Fernando Carmona, J. M. Ortega, J. Silva, Vicente La Barrera) o a extranjeros radicados en Chile (el italiano Alejandro Cicarelli, primer director de la Academia de Bellas Artes, fundada en 1849).

7 El catálogo de la exposición precisa que algunos objetos fueron adquiridos en Roma en 1872, en el remate de la colección de monseñor Badía, mientras que una tapicería de los gobelinos provenía de "la venta de los muebles de unos de los castillos vecinos de París, realizada a consecuencia de la invasión de los prusianos". 
más adecuado a las aspiraciones de las elites. La colección de Maximiano Errázuriz da cuenta de este fenómeno, al no solo excluir los objetos producidos en América, sino que además al manifestar un gusto orientado al neoclásico (colección de copias de bustos romanos) y a las producciones francesas e italianas desde los siglos Xv hasta principios del xix. Algunas de las joyas de esta colección eran un reloj imitación Boulle, una tapicería de los gobelinos del siglo xvir y un retablo italiano de 1417.

La exposición, en este sentido, puede ser pensada como una instancia pedagógica que fomentó la conformación de nuevos parámetros de buen gusto mediante la distinción entre "mamarrachos" y arte verdadero. El término mamarracho, que se refiere a las cosas mal hechas, condenaba el arte colonial contraponiéndolo a un academicismo fomentado por los intelectuales liberales, que ensalzaba la herencia grecolatina y francesa (Acuña; De la Maza). Este "buen gusto" está referido a un estilo funcional (o a un conjunto de estilos) que prevalece en el tiempo frente a las modas pasajeras, lo que era un tópico a nivel internacional que se venía desarrollando desde la defensa del clasicismo para la Exposición de Londres de 1851. Casi sesenta años después de la exposición, era ya un discurso muy instalado, tal como se puede apreciar en una conferencia de 1937 realizada por el arquitecto Ricardo Larraín Bravo, donde señala que el buen gusto tendría su correlato en la validación de ciertos estilos, siendo impermeable a lo efímero de los fenómenos de moda y consagrando los objetos o formas cuyo estudio (y juicio favorable) resistiría al paso del tiempo. Existiría así un "eterno buen gusto", fijado "por la distinción y la delicadeza que nos muestran las obras maestras de los hombres, y que han merecido el respeto y la devoción seculares de las generaciones siguientes" (Vizcaíno 154). En consecuencia, el buen gusto se inscribiría en una larga duración y actuaría como una forma de reproducción social, puesto que no sería posible apartarse de sus cánones sin caer en el mal gusto. En 1937, cuando Larraín escribió estas palabras, los cánones arquitectónicos instalados correspondían efectivamente al neoclasicismo, pero el arquitecto no parece reparar en lo paradojal de su discurso, ya que por una parte, para llegar a estos cánones hubo que desechar los coloniales, es decir, romper con una tradición validadora, y por otra, ignora el retorno progresivo de lo colonial que opera a partir de la década de 1920, lo que se tradujo en la organización de exposiciones y en el uso de elementos arquitectónicos en las construcciones.

\section{Los nuevos patrones del "buen gusto": la Exposición Internacional de Santiago de 1875}

Una vez que lo colonial fuera condenado y poco a poco relegado del entorno visual y material más inmediato de las familias de elite, estas debieron buscar cómo volver a amoblar sus casas. A dos años de la Exposición del Coloniaje, se organizó la Exposición Internacional de Santiago de 1875, la que promovió nuevos patrones 
estilísticos y de consumo en el flamante edificio de la Quinta Normal, ubicado en el sector norponiente de la ciudad y construido para la ocasión. Además de la apertura internacional que implicó esta exposición, por su alto grado de preparación y de difusión, el evento fue una vitrina importante para la puesta en escena de los valores de la modernidad y de su materialidad. Sin embargo, no fue el único espacio donde se presentaron los nuevos patrones del buen gusto: por ejemplo, el comercio empieza a ejercer un rol importante en este sentido, con el aumento de comerciantes europeos que operan en Santiago a partir de 1849. De hecho, Jacqueline Dussaillant, en su estudio sobre el nacimiento de la sociedad de consumo en Chile, subraya que las casas de novedades e importadoras se encontraban en manos de empresarios franceses e ingleses en la segunda mitad del siglo xIx. En el caso del comercio minorista, si bien estaba dominado por chilenos, los establecimientos en manos de extranjeros estaban representados en un $60 \%$ por franceses, seguidos por los españoles, con un $18 \%$. Este mismo periodo vio la inauguración de las casas de novedades más importantes y de mayor prestigio en Santiago: Casa Muzard (1845), Jouve \& Gorlier (1847), A la Ville de Paris (1850), Casa Francesa (1859) y Casa Pra (1865) (Dussaillant 87-88). A su vez, otro factor a considerar fue el aumento de los viajes de chilenos a Europa a partir de 1850, lo cual contribuyó a la conformación de una representación europea desde los americanos y a los fenómenos de transferencia cultural (Sanhueza, "En busca de un lugar en el mundo").

A pesar de estas instancias intermedias, no fue hasta la exposición de 1875 que se concretó la ambición de realizar un evento que pudiera equipararse, por lo menos en lo discursivo, con las exposiciones que se realizaban en Europa y Estados Unidos. Impulsada por el gobierno de Federico Errázuriz (1871-1876), tenía por objetivo ser uno de los testimonios "más elocuentes de la grandeza de nuestros destinos" (Correo de la Exposición, 16/09/1875, 2). En este sentido, integró productos naturales e industriales, nacionales y extranjeros, relacionados con la agricultura, la ganadería, la minería y su maquinaria, la industria, la construcción, lo militar, lo naval, , las ciencias físicas, sin olvidar las bellas artes y sus derivados (Programa y reglamento). Abierta desde el 16 de septiembre de 1875 al 9 de enero de 1876, fue un ejercicio preparatorio para la Exposición del Centenario de Filadelfia, a realizarse en 1876, donde Chile iba a mandar distintos artículos de su producción nacional.

En lo relativo a las artes decorativas, cabe destacar que fueron integradas por primera vez a varios de los grupos de exhibición, dentro de la tercera sección, dedicada a la industria y manufactura. ${ }^{8}$ De estos objetos, los distintos cronistas que visitaron la exposición subrayaron los exhibidos por Francia, que decidió construir un pabellón

8 Las artes decorativas estaban particularmente presentes en los grupos 16 ("Mueblería, tapicería y en general artículos de decoración i ornamentación de habitaciones"), 17 ("Trabajos de metales preciosos i sus imitaciones; joyería i artículos de lujo"), 18 ("Ferretería i mercería en general, quincallería i broncería; cuchillería") y 19 ("Cristales i vidrios. Porcelanas i lozas; manufacturas cerámicas en general"). 
propio luego de que la comisión organizadora diera el hall central de la Quinta Normal a la comitiva alemana (Roco, 182). ${ }^{9}$ Según la Guía del visitante, el anexo francés ocupaba "un espacio de 80 metros de largo y 20 de ancho, sostenida su techumbre abovedada, y cubierta de cristales, por 68 columnas de fierro macizo, aunque livianas y elegantes" (12), es decir, contaba con una superficie de $1.600 \mathrm{~m}^{2}$, dividida en tres franjas, además de una casa en las afueras del pabellón, que debía albergar "un amueblado completo" (Roco 14). Había sido enteramente construido en Francia, para ser rearmado en Chile un par de semanas antes de la inauguración de la exposición.

Este pabellón fue sin duda uno de los más comentados por los cronistas, ya que consideraban a Francia como "la campana destinada a llevar la voz de orden, [...] el pregonero universal de las naciones, la voz que todos oyen i a cuyos ecos se apresuran todos a responder" (Roco 15). En este sentido, la admiración por Francia responde al momento de su máximo esplendor como referente de civilización y modernidad, pensada como un conjunto de valores e ideas que se proyectan no solo en hábitos, sino también en productos.

Fueron los objetos de lujo los que recibieron la mayor atención, ya que Francia presentó "un conjunto de productos industriales de gran gusto, de los cuales París, la capital del mundo, siempre tuvo el monopolio" (Correo de la Exposición, 16/09/1875, 19-21). Entre ellos, destacaban el mobiliario, las distintas piezas de las tapicerías de Aubusson, las persianas bordadas, los cristales de Baccarat, los laqués de Christofle, las lozas de Creil-Montereau, las lámparas arañas y los bronces, las chimeneas esculpidas y las porcelanas de Sèvres, es decir, un conjunto de lujosos productos que permitía a las elites renovar enteramente sus interiores y ponerse de esta forma a la altura de los interiores de las elites europeas (Correo de la Exposición, 16/09/1875, 19-21).

Sin embargo, quizás no todos los objetos presentados eran genuinos, y en las palabras irónicas de Ramón Subercaseaux, "como el buen discernimiento en todo era imposible, se compraba con todavía mayor estimación el lote de estatuas de pacotilla, cinceladas en mármol florentino, y miles de otros objetos de arte falsos que salieron de Europa a deslumbrar por primera vez en nuestras apartadas playas" (232-33). De esta forma, la falta de educación artística de las elites chilenas les impidió discernir entre lo auténtico y lo falsificado, volviéndose objeto de burla de parte de algunos de sus propios miembros.

Este fenómeno se puede deber a que esta elite, que tomó como referencia a Francia desde la década de 1850, cuando se intensificaron las relaciones diplomáticas entre los dos países, no tuvo como modelo la cultura de corte del Antiguo Régimen, con

9 En palabras del cronista, "el gran salón del Palacio fue dado a los alemanes, i los franceses, que vieron en esto un desaire, para exhibir dignamente i con el lujo necesario sus productos, pidieron terrenos al Directorio de la Exposición i encargaron el edificio que hoi llama la atención de todos i es una de las preciosidades del Parque". La comitiva alemana se podía considerar como la competencia directa de Francia, incluso su enemiga, ya que la derrota francesa frente a Prusia en 1870, a la par con la proclamación del imperio alemán en el palacio de Versalles en 1871, alimentaron la enemistad hasta el desencadenamiento de la Primera Guerra Mundial en 1914. 
altos grados de sofisticación, sino la de Napoleón III (Segundo Imperio). ${ }^{10}$ Esta corte también se encontraba en proceso de sofisticación, ya que era de reciente elevación y proveniente, en parte, del mundo militar y burgués. Era objeto de burla por parte de la aristocracia de Antiguo Régimen, que en ese entonces estaba refugiada en Faubourg Saint-Germain, aunque también en proceso de integración mediante alianzas matrimoniales. En este sentido, la elite chilena tuvo un proceso de sofisticación de modales -con nuevos patrones de comportamiento y el aprendizaje de los usos correctos de objetos- a partir de su experiencia con la corte de Napoleón inI, lo que explicaría sus rasgos burgueses que hacen difícil clasificarla en cuanto a elite. Por otra parte, esto explicaría también el rechazo que enfrentaron las elites chilenas -al igual que otras elites latinoamericanas- de parte de la vieja guardia del Faubourg Saint-Germain, que no reconoció sus estándares, relegándola al ostracismo en la capital francesa y calificando sus miembros de rastaquouère (Berchenko). ${ }^{11}$

La dificultad de asimilar los complejos códigos de comportamiento de las elites europeas se ve reflejada, por ejemplo, en el manejo de los utensilios ligados a la alimentación. En el catálogo de la cristalería Baccarat, presentado para la exposición, se detallan servicios completos que incluyen hasta once tipos de copa, de distintos tamaños y colores, cada uno con un uso particular (agua, vino, champaña, oporto, coñac, jerez, licor dulce) (Artículos de cristal y de porcelana 12-3). Había vajillas compuestas por más de 1.600 piezas, que incluían cuatro tipos de plato (extendido, sopero, postre, dulce): por ejemplo, el servicio número 365 ("festonado púrpura, gran juego, filetes y perillas doradas”) se componía de 1.607 piezas, entre ellas 288 platos, soperas, fuentes, azafates, coladeros, salseras, ensaladeras, rabaneras, compoteras, fruteras y hueveras, además de un completo servicio de té y café (tazas, azafates, compoteras, mantequilleras) (Artículos de cristal y de porcelana 18-9). La figura 1 muestra una sopera adquirida en 1898 por Luis Vergara Vergara. Proveniente de la Royal Worcester Vitreous (Inglaterra), la porcelana posee incluso el monograma de la familia Vergara, lo que indica que se trata de un encargo personal.

El correcto conocimiento y uso de los servicios implicaba la existencia de instancias de socialización de los modales. En este aprendizaje, un papel importante lo cumplían las institutrices extranjeras o los manuales de urbanidad, como el Manual de urbanidad y buenas maneras de Manuel Antonio Carreño, que fue constantemente

10 El primer representante chileno en Francia fue Francisco Pérez Rosales, encargado de Negocios desde 1836 a 1853, fecha en la que Manuel Blanco Encalada asume como Ministro Plenipotenciario. El cambio en el rango de la representación diplomática, además de la trayectoria de Blanco Encalada, que fue presidente, auguran un periodo en que los diplomáticos chilenos estuvieron más integrados a la vida de la corte imperial. El lazo personal del Blanco Encalada con Napoleón III se refleja en el hecho de que la boda de su hija Teresa fue apadrinada por la pareja imperial. A su vez, se fortaleció gracias al matrimonio de su hijo Florencio (-1890) con la princesa rusa Olga Trubetskoy (1820-1896), viuda en 1849 del príncipe Mikhail Oustinov. Olga estaba emparentada con la duquesa de Morny, cuñada de Napoleón III, nacida Sofia Trubetskoy.

11 El término rastaquouère es un neologismo formado por las palabras "raspa" (del verbo "raspar") y "cuero" y se refiere al origen de las fortunas de ciertos sudamericanos. Se volvió rápidamente peyorativo, designando nuevos ricos que ostentaban con mal gusto sus fortunas, independientemente de su origen geográfico. El rastaquouère se integró luego a la literatura y al teatro, bajo la forma de personajes caricaturizados y a menudo ridículos. 


\section{FIGURA 1}

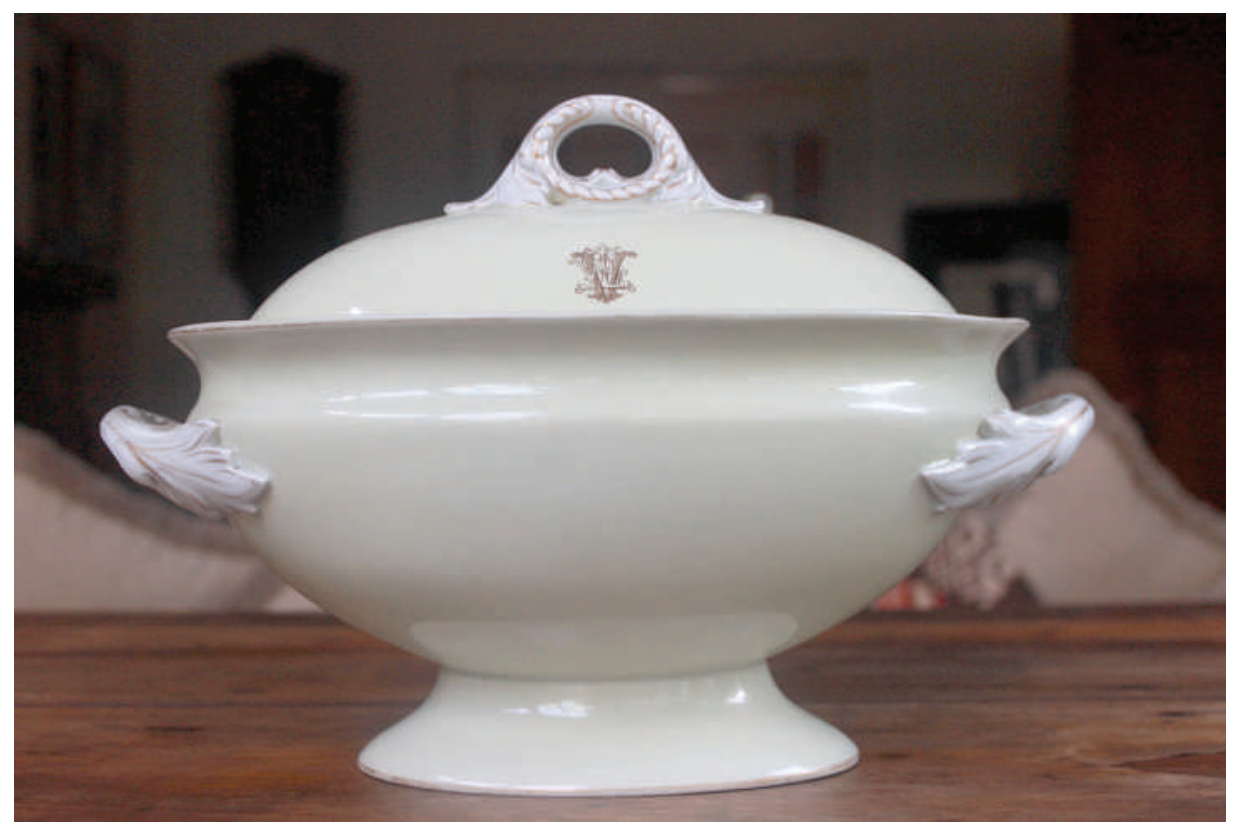

Sopera de porcelana blanca de Luis Vergara Vergara, 1898, Royal Worcester Vitreous. Colección particular.

reeditado desde su primera publicación chilena en $1863 .{ }^{12}$ El artículo 3 de este manual se refiere exclusivamente a la mesa, por ser el lugar "donde más clara y prontamente se revela el grado de educación y de cultura de una persona, por cuanto son tantas y de naturaleza tan severa, y sobre todo tan fáciles de quebrantarse, las reglas y la prohibición a que está sometida" (98-9). Frente a tal dificultad, Carreño dedica incluso varios puntos al uso y fin de los cubiertos, de manera de que no exista traspié al momento de sentarse a una mesa. Este tipo de literatura se puede analizar desde diversas ópticas, entre ellas la adscripción a una "moral de las apariencias", que dicta el comportamiento del hombre en relación con los otros (moral social), pero desde una vertiente estética, es decir, desde una "moralidad de las bellas apariencias" (Cataldo). Por otra parte, la historiografía (Soaje; Lander) ha destacado el rol de esta literatura en la formación de un ciudadano moderno, con nuevos hábitos y sensibilidades, capaz de vivir y de representar el modelo político-social que se buscaba implantar en los

12 Resulta difícil aventurar, en el estado historiográfico actual, si la importación de nuevos objetos fue anterior, posterior o concomitante con la modificación de los patrones de conducta. En este sentido, resultaría interesante estudiar de manera más fina la cronología de estos fenómenos, prestando especial atención a las nuevas instancias educativas, como lo eran los manuales de urbanidad, las institutrices extranjeras y los colegios, sobre todo los que fueron fundados por órdenes religiosas en el siglo XIX y que estaban particularmente a cargo de la educación de los niños de elite, como por ejemplo el colegio del Sagrado Corazón, estudiado por Alexandrine de La Taille (2012). 
países independizados de España, desde "la necesidad de asimilar las élites criollas a los cánones de la sociedad europea civilizada" (Soaje 197). En este sentido, se trata de un modelo común a muchos países del continente, que buscó formar un nuevo hombre, incluso desde lo pedagógico, ya que estos manuales se adaptaban para la escuela (Toro).

Ahora bien, si a nivel discursivo Francia parecía ser el único referente válido, a nivel de productos presentados y premiados, su hegemonía debe ser relativizada. Debemos separar el estilo del origen nacional de los objetos. Por ejemplo, en su estudio sobre la colección de arte de los Cousiño Goyenechea, que fue parcialmente presentada en la exposición de 1875, Rosario Willumsen muestra que si bien Francia era un referente indiscutible a la hora de comprar pinturas y esculturas, no impedía que artistas de otras nacionalidades fueran llamativos, en particular los italianos. ${ }^{13}$ Los premios atribuidos a los objetos del grupo 19 ("Cristales i vidrios. Porcelanas i lozas; manufacturas cerámicas en general”) ponen de manifiesto una tendencia similar, con Estados Unidos con el mayor número de medallas (cinco medallas de primera categoría, seis de segunda categoría y cuatro de tercera categoría: un total de quince medallas); seguido por Bélgica e Inglaterra, con un total de siete medallas; Alemania y Francia, con un total de cinco medallas, y finalmente Chile, con dos medallas (AN, Exposición Internacional de 1875, vol.10, fs. 118). Sin embargo, es muy probable que la gran mayoría de los objetos presentados y premiados tuviera como matriz los estilos impuestos por Francia, aunque no lo podemos comprobar del todo por las escasas descripciones y registros con los cuales contamos.

Por último, la exposición de 1875 generó una visualidad que se expresó en los diferentes soportes de difusión con que contó. Se editaron varios catálogos (general, por sección o por expositor) ${ }^{14}$ y un diario exclusivo de la instancia (Correo de la Exposición, 1875-1876), los que en algunos casos contaban con grabados de los productos exhibidos, en su gran mayoría maquinarias y esculturas. Resulta particularmente interesante el catálogo de la casa comercial Rose Innes y Ca., que tenía 374 páginas con numerosos grabados, donde se indicaba el número del objeto, su precio y eventualmente una descripción que aclaraba su uso. Sin embargo, fueron pocas las reproducciones de objetos pertenecientes a la categoría de las artes decorativas: se limitaron a algunos ejemplos de pilas, jarrones, estantes para flores, estantes para sombreros y mesas de

13 En este artículo, Willumsen muestra que la colección de pinturas de los Cousiño integraba en su gran mayoría artistas europeos (97\%), provenientes de Francia, Italia, Alemania, España, Holanda, Bélgica e Inglaterra. Las esculturas presentaban un patrón similar, y sus artistas eran casi exclusivamente de Francia e Italia (95\%), con un pequeño porcentaje de chilenos (5\%).

14 La Exposición contó con los siguientes catálogos: Catálogo general de la Exposición Internacional de Chile en 1875. Sección IV. Bellas Artes e Ingeniería (1875); Catálogo de los objetos que se remiten a la Exposición Internacional de Santiago de Chile (1875); Exposición universal de Chile: catálogo del Salvador (1875); Catálogo especial de los objetos expuestos por las casas representadas por J. y H. Prieto en la Exposición Internacional de Chile 1875 (1875); Artículos de cristal y de porcelana que por sí y en representación de la Compañía de Cristalería de Baccarat presentan Antonio Maldini y Ca. (1875); Catálogo ilustrado de lo expuesto por Rose Innes y Ca. en su anexo: exposición internacional de Chile, Santiago, septiembre 16 de 1875. (1875). 
mármol. Entre ellos, se encuentra una pila bronceada, publicada bajo el número 641 con la descripción de "Forma niño. Taza forma hojas. Alto 2,5 pies" (fig. 2). En este objeto, de $76 \mathrm{~cm}$, el toque clásico está dado por la figura del niño desnudo (aunque con sus partes genitales cubiertas por una tela), es decir, un putto.

Esta práctica de impresión supone entender la imagen como un dispositivo que permite poner los objetos en situaciones deseables, los que, en este contexto, son decodificables como portadores de modernidad. A este fenómeno contribuye el desarrollo de nuevas técnicas de producción y reproducción de imágenes, lo que a su vez permitió la articulación de nuevos circuitos de circulación icónica de este tipo de artefactos (Amigo; Wasserman; Malosetti; Metzeltin). El registro visual se constituyó así en un testimonio del progreso y una forma de representar al ciudadano dotado de un aura de modernidad. Se trata, por ende, de un discurso moderno construido y validado desde el cambio de la realidad material y su expresión visual en distintos registros.

\section{Habitar y amoblar el espacio: de la exposición al palacio}

Una vez promovido el nuevo modelo de ciudadano mediante instancias como la Exposición Internacional de 1875, se intentó validarlo al integrar sus expresiones materiales al espacio doméstico. Si bien la construcción discursiva de la nación se expresó en un primer momento en la renovación del concepto de espacio público y luego en su aplicación concreta - mediante el plan de Vicuña Mackenna para Santiago-, también debía tener un correlato en el ámbito privado de las elites. De esta forma, el discurso de lo moderno implicó una redefinición de la relación entre el sujeto y su habitar, y en definitiva, de la satisfacción de sus nuevas necesidades. Es decir, este nuevo sujeto moderno demandó un mundo de objetos que, en su apropiación y uso, testimoniaba una condición de civilizado que se adquiría en la última etapa del proceso de sofisticación. A su vez, debía proporcionar un marco que fuera adecuado para estos objetos, con el fin de dar coherencia entre el contenedor y el contenido. Por esta razón, al mismo tiempo de cambiar las artes decorativas que amoblaban y ornaban sus viviendas, la elite santiaguina procedió a renovar sus casas a partir de la década de 1860, transitando desde la casa colonial con patio hacia el palacio, adaptado del modelo del hotel particular. De esta forma, el palacio, con recursos arquitectónicos neoclásicos y eclécticos, venía a complementar el nuevo panorama urbano, además de manifestar el anhelo de inscripción de las elites chilenas en un mundo cosmopolita, sin menospreciar la inversión y la eventual plusvalía inmobiliaria que podía conllevar (Bergot; Bergot, Vergara y Vizcaíno).

En el interior del palacio, el proyecto moderno implicó asociar dos dimensiones del habitar: por una parte, el confort como expresión propia de la modernidad y, por otra, el lujo como manifestación particular a las elites. De este modo, el lujo, más allá del aspecto estético sometido a la volatilidad de la moda, puede ser definido como "una riqueza magnificada por una ética y una estética de la profusión" (Perrot 


\section{FIGURA 2}

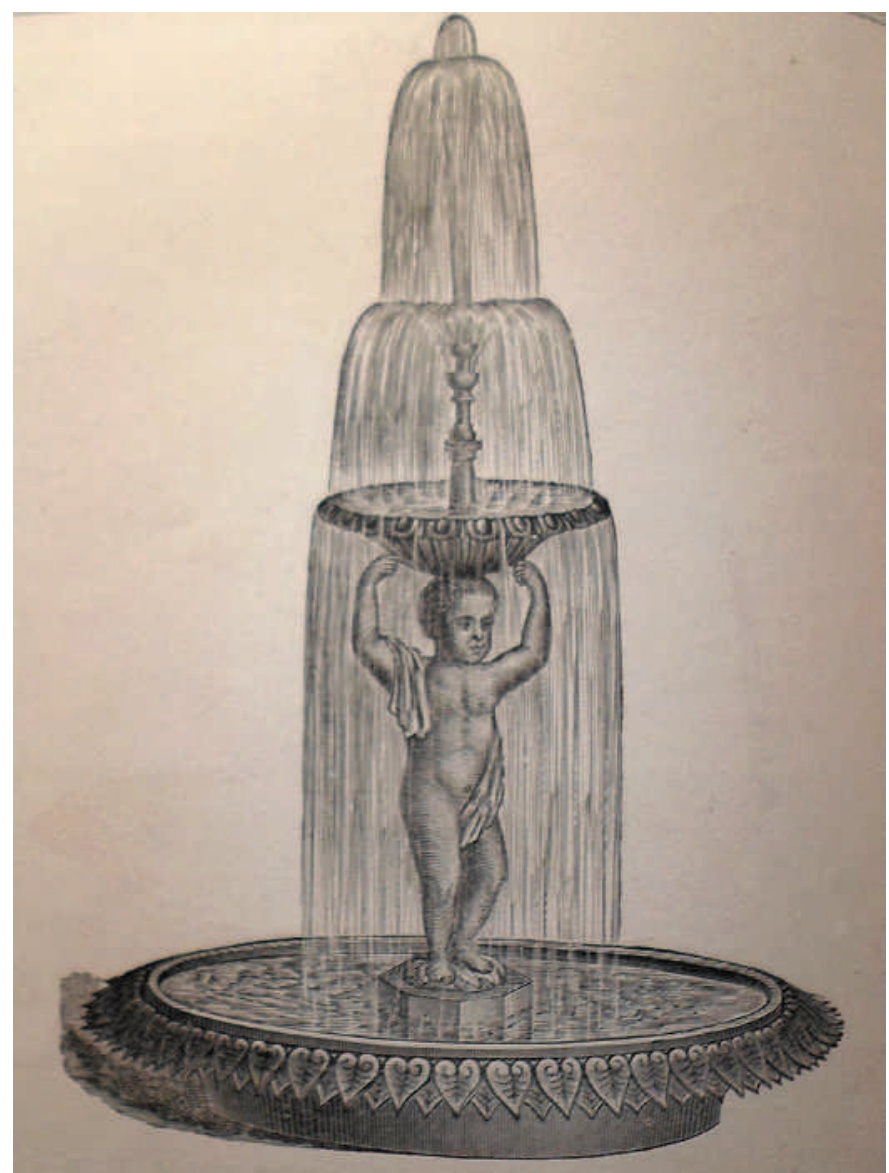

Pila bronceada. Catálogo ilustrado de lo expuesto por Rose Innes y Ca en su anexo: exposición internacional de Chile (Valparaíso: Imprenta del Mercurio, 1875), 232.

9), que se caracteriza por gastos suntuarios a menudo calificados de inútiles puesto que no responden a una necesidad. En palabras de Ramón Subercaseaux, la década de 1870 vio el despegue del lujo en Chile, gracias a "los buenos negocios de minas, y por las riquezas, reales o aparentes, que venían trayendo a circular los propietarios, capitalistas o especuladores de las diferentes partes del país" (229). Sin embargo, el lujo -que vino a romper con la austeridad colonial de las costumbres chilenas- no se instaló sin resistencia: se criticó que su aumento era un factor de desgaste (y hasta de pérdida) del capital económico de ciertas familias de elite y que corrompía a la mujer respecto de su deber de esposa, madre y dueña de casa (Fernández). A su vez, afectaba a los hombres al apartarlos de la vida pública, es decir, del cumplimiento de su deber como ciudadanos (Mac-Iver). 
A la dimensión del lujo se agrega, en el transcurso del siglo xix en Occidente, una ingeniería de la comodidad, que se caracteriza por "una creciente preocupación del bienestar y del calor, la obsesión cada vez mayor por lo interior y lo familiar, el gusto por el acolchado y el relleno, el forro y el forrado" (Perrot 9-10). Así, las artes decorativas que poblaban los palacios de las elites chilenas no solo simbolizaban la penetración de nuevos modos de vivir, más íntimos y confortables, sino que también constituían el símbolo de un consumo naciente ligado al estatus; ambas dimensiones visibilizan las diferencias sociales y modifican la relación entre riqueza y prestigio personal o familiar.

Un ejemplo de este fenómeno se puede apreciar en la incorporación de nuevos espacios en los planos de las viviendas en el transcurso del siglo xix. Entre ellos, podemos señalar la pieza de baño, cuya aparición puso de manifiesto nuevos patrones de higiene que emergieron desde un discurso científico, pero que también dieron cuenta de una modificación de las normas olfativas a través de un fenómeno de desodorización que tuvo lugar entre los siglos XVIII y XIX (Corbin). Para amoblar este nuevo espacio, se puso a disposición de los usuarios distintos artefactos, tales como la tina de cuerpo entero, con un sistema de calefacción a gas (fig. 3), que se presentaba en el catálogo de la casa comercial Rose Innes y Ca.

Este nuevo habitar también se expresó en los salones y el hall de entrada: de esta forma, este último ya no era un mero espacio de acceso, sino que se convirtió en una primera instancia de recepción y de uso del espacio público. También podría haber marcado un primer nivel de discriminación entre los visitantes, aunque este uso no queda comprobado. De esta manera, su conformación y amueblamiento debían dar cuenta del capital social y estético de la familia, pero también de su comprensión de los cánones ligados a la comodidad. Un ejemplo de ello se puede apreciar en una fotografía del palacio Subercaseaux de principios del siglo xx (fig. 4), donde aparece el hall de entrada, reminiscencia del patio colonial que ha sido cubierto para conservar la iluminación cenital. Se perfila como un espacio de espera por las numerosas sillas, pero también de uso de la familia por los sillones y la mesa, sobre la cual se encuentra dispuesto un juego de té. A su vez, si bien adquiere un matiz cálido por la alfombra central y las plantas, conserva una apariencia solemne por su ornamentación neoclásica y sus jarrones. También revela su dicotomía entre espacio público, por estar a la entrada de la casa, y espacio privado, dado que las fotografías de la familia están dispuestas sobre una mesa al fondo, introduciendo al visitante en la semifamiliaridad de los dueños de casa.

Por otra parte, tal mundo de objetos requería de la existencia de un patrón de comportamiento activo de parte del usuario, ya que este debía adquirir las competencias deseables para discriminar, seleccionar y establecer relaciones entre los objetos como parte de un discurso que le permitía acceder a una experiencia de modernidad. Creemos que es el conjunto de estas normas y comportamientos lo que empieza a configurar el estilo de vida propio de las elites civilizadas de este periodo. Es importante destacar 
FIGURA 3

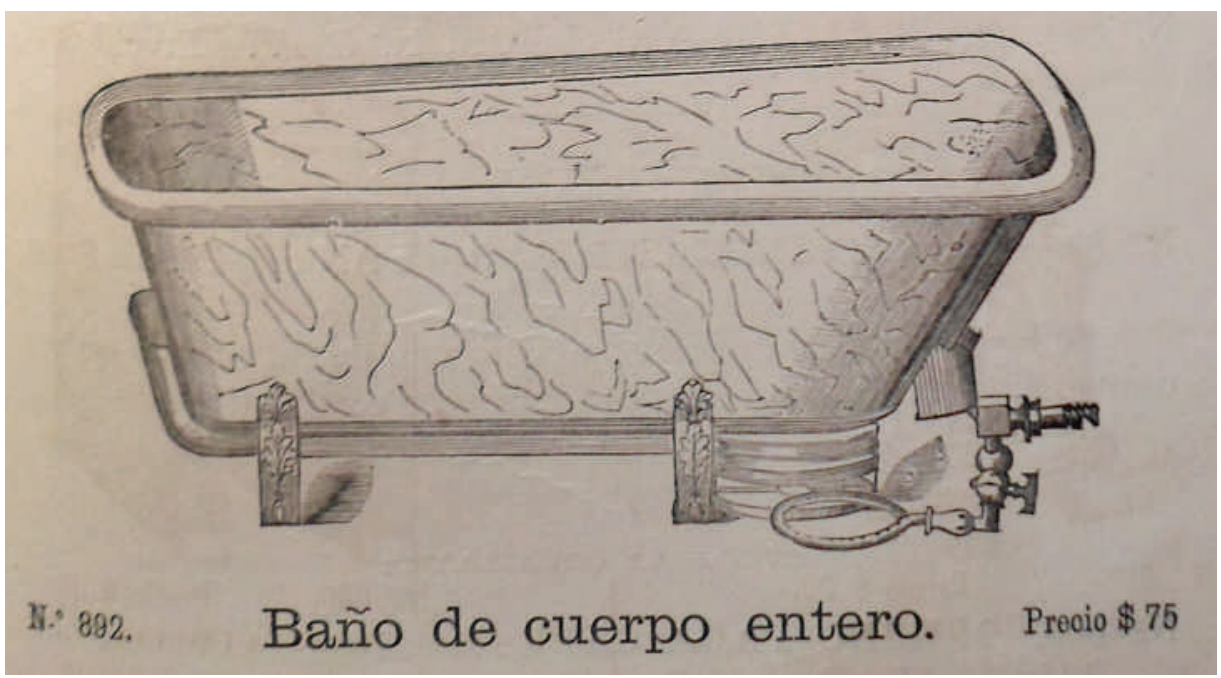

Tina de cuerpo entero. Catálogo ilustrado de lo expuesto por Rose Innes y Ca. en su anexo: exposición internacional de Chile. Valparaíso: Imprenta El Mercurio, 1875, 297.

\section{FIGURA 4}

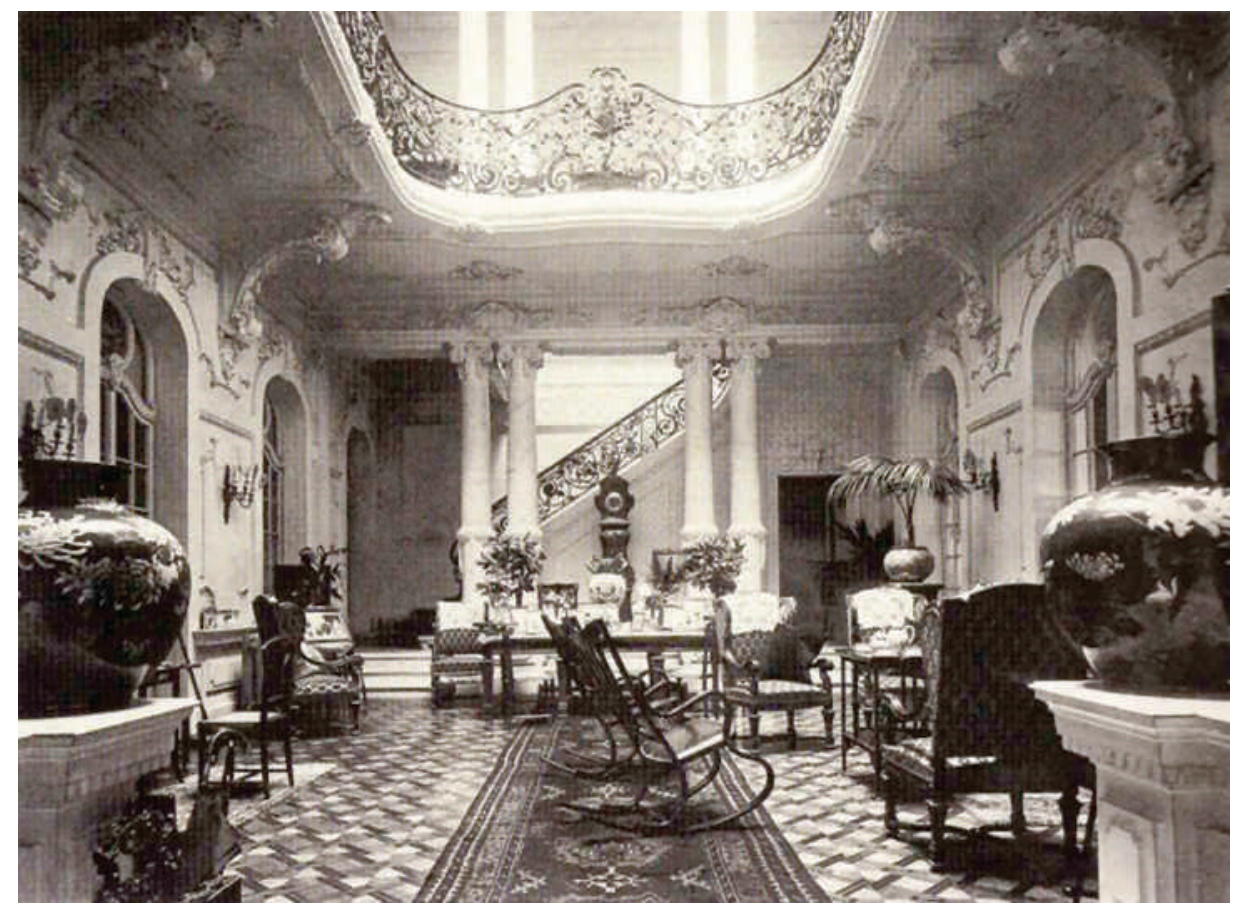

Hall del palacio Subercaseaux a inicios del siglo xx. Club Fuerza Aérea de Chile. 
a este respecto que el concepto de "estilo" se manifiesta en dos niveles que operan de forma simultánea: por una parte, actúa como testimonio del sujeto civilizado y, por otra, valida socialmente los objetos concebidos bajo el alero de lo moderno. De esta forma, el estilo actúa como categoría de subjetivación y de posicionamiento social, donde el objeto posibilita ambas dimensiones de representación: es un testimonio para uno mismo y, a su vez, para un otro.

Es importante recalcar que la instalación de lo moderno no pasó solo por un sistema de apropiación de objetos significantes, sino también por circuitos de sociabilidad, en que el estilo asociado a la validación de un gusto puso en valor lo estético, las pautas de conducta y los objetos deseables. De esta forma, siguiendo lo planteado por Michael Baxandall, los estilos se pueden entender como un sistema de códigos y valores comprensibles que forman elementos base de una sociabilidad propia, ${ }^{15}$ es decir, el conjunto de materialidades asociadas al discurso de lo moderno adquiere valor en la medida en que genera un conjunto de prácticas sociales, mediante las que los miembros de un grupo se reconocen y validan mutuamente. En este escenario, las prácticas y los espacios de sociabilidad y exhibición adquieren una dimensión clave, al mismo tiempo que generan una visualidad que se extiende, a través de una industria cultural de acompañamiento, a un contexto social mayor. ${ }^{16}$ En el caso chileno del siglo XIX, extrapolable a otras sociedades que se enfrentaron a la problemática de equiparar el nivel de "civilización" mostrado por las potencias industrializadas de su época, mientras las elites introdujeron un conjunto de objetos en su ámbito privado y les otorgaron un valor simbólico asociado al ciudadano moderno, la industria cultural los puso en circulación y expandió paulatinamente sus claves de validación a una creciente clase media a finales del mismo siglo.

\section{Reflexiones finales}

Las exposiciones realizadas en Chile en la década de 1870, en particular la Exposición del Coloniaje de 1873 y la Exposición Internacional de Santiago de 1875, se desarrollaron, a nivel discursivo, sobre las nociones de progreso y de modernidad, al mismo tiempo que daban cuenta del proyecto sociopolítico que las elites idearon después del proceso de Independencia, proyecto que se construyó en oposición a lo "colonial" como herencia de un pasado monárquico y oscurantista.

\footnotetext{
15 Si bien Baxandall trabaja el concepto de gusto en relación con el ámbito artístico, sus postulados se pueden utilizar para el análisis de las artes decorativas y las expresiones estilísticas del ciudadano de finales del siglo xix en Chile, en tanto el conjunto de objetos y la visualidad asociada conforman prácticas que exceden los ámbitos propiamente artísticos para expresarse como parte de una cultura visual y material.

16 En sociología, una industria cultural de acompañamiento se refiere al conjunto de dispositivos mediales, comerciales y productivos que ponen en circulación una serie de objetos y sus prácticas culturales. En el presente caso, un ejemplo corresponde al Correo de la Exposición, pero también a la prensa en general, o a las casas comerciales.
} 
Este artículo, desde una perspectiva exploratoria y pluridisciplinar, indaga en un aspecto específico de este proyecto de nación, a saber, la emergencia de nuevos patrones del "buen gusto" en el ámbito doméstico de las elites. En este sentido, las exposiciones de la década de 1870 ponen en escena la transición que afecta a las artes decorativas, el abandono de lo colonial y el surgimiento de los cánones neoclásicos en la arquitectura pública y, por lo menos discursivamente, de los estilos franceses en lo ornamental.

A su vez, el discurso material de la elite constituye las bases de la construcción de un espacio público que redefine las implicancias de la elite en el campo político, cultural y económico. En este contexto, se promueve la aparición de nuevos sujetos y categorías sociales que amplifican las nociones de Estado, ciudadano y proyecto político. Las exposiciones de artes decorativas y, por ende, el mundo de los objetos, testimonian una experiencia moderna propia del sujeto en su expresión pública y política, la que, aparejada con pautas de consumo cultural, construyen una nueva dimensión del ser ciudadano.

Sin embargo, el proyecto material de la elite no tuvo el éxito que probablemente el estamento esperaba. Por una parte, emerge en forma concomitante una crítica al lujo, que surge de la misma elite y de los sectores medios en conformación, abriendo las bases para un debate público más allá de la intimidad propia de los hogares-palacios. Es un aspecto que sería sin duda interesante estudiar para mostrar las resistencias al nuevo modelo que se intentaba difundir. En este sentido, el rescate de la expresión material de la elite dice relación con la construcción de un escenario donde la dimensión pública se encuentra asequible como experiencia de ciudad y ciudadanía, tanto para la elite como para las capas medias y populares. Por otra parte, se podría interrogar la tensión entre lo "moderno" y lo "colonial" desde el hecho de que, si bien la elite adoptó los nuevos patrones de gusto en sus residencias capitalinas, conservó la decoración colonial en el campo. El estudio de este fenómeno y sus causas permitiría sin duda rastrear otro tipo de resiliencia del gusto colonial; asimismo, relativizaría el impacto de un modelo cultural y aclararía mecanismos de transferencia.

\section{Referencias}

Acuña, Constanza. Perspectivas sobre el coloniaje. Santiago, Ediciones Universidad Alberto Hurtado, 2013.

Amigo, Roberto. Imágenes de la historia y discurso político en el Estado de Buenos Aires (1852-1862). Arte argentino de los siglos XVIII y/o XIX. Buenos Aires, FIAAR, 1998.

Anderson, Benedict. Comunidades imaginadas: reflexiones sobre el origen y la difusión del nacionalismo. México, Fondo de Cultura Económica, 1983.

Archivo Nacional, Exposición Internacional de 1875, vol. 10. Documentos manuscritos. Artículos de cristal y de porcelana que por sí y en representación de la Compañía de 
Cristalería de Baccarat presentan Antonio Maldini y Ca. Valparaíso, Imprenta del Universo, 1875.

Bauer, Arnold J. Goods, Power, History. Latin America's Material Culture. Cambridge, Cambridge University Press, 2001.

Baxandall, Michael. Pintura y vida cotidiana en el Renacimiento, Barcelona, Editorial Giunti, 1988.

Berchenko, Pablo. "Paris dans les représentations des élites chiliennes au xixème siècle. De Pérez Rosales à Blest Gana”. Cahiers d'études romanes, vol.6, 2001, pp. 63-75.

Bergot, Solène. "Unidad y distinción: el eclecticismo en Santiago en la segunda mitad del siglo xix”. Revista 180, n² 23, 2009, pp. 32-35.

Bergot, Solène, Enrique Vergara y Marcelo Vizcaíno. "Palacio Vergara: élite y arquitectura en Santiago a fines del siglo XIx”. Arquitectura revista [En línea], vol. 10, $\mathrm{n}^{\circ}$ 2, pp. 70-77 (http://revistas.unisinos.br/index.php/arquitetura).

Carreño, Manuel Antonio. Compendio del manual de urbanidad y buenas maneras. Valparaíso, Imprenta y Librería del Mercurio de Santos Tornero, 1863 [1854]. Cataldo, Gustavo. "Las buenas maneras o la moral de las apariencias". Humanidades, vol. 10, 2005, pp. 7-19.

Catálogo ilustrado de lo expuesto por Rose Innes y Ca. en su anexo: exposición internacional de Chile, Santiago, setiembre 16 de 1875. Valparaíso, Imprenta El Mercurio, 1875.

Catálogo razonado de la Exposición del Coloniaje celebrada en Santiago de Chile en septiembre de 1873 por uno de los miembros de su comisión directiva. Santiago, Imprenta del Sud-América de Claro y Salinas, 1873.

Corbin, Alain. Le miasme et la jonquille. Paris, Champs Flammarion, 1986.

Correo de la Exposición, Santiago, 1875-1876. Impreso.

De la Maza, Josefina. De obras maestras y mamarrachos: notas para una historia del arte del siglo diecinueve chileno. Santiago, Metales Pesados, 2015.

De La Taille, Alexandrine. Educar a la francesa. Anna du Roussier y el impacto del Sagrado Corazón en la mujer chilena (1806-1880). Santiago, Ediciones Uc, 2012.

Drien, Marcela. "Coleccionistas en la vitrina: expertos, filántropos y modelos del buen gusto". El Sistema de las Artes. VII Jornadas de Historia del Arte. Ed. Angela Brandao et al. Santiago, Museo Histórico Nacional, 2014, pp. 131-138.

Dussaillant, Jacqueline Las reinas de Estado. Consumo, grandes tiendas y mujeres en la modernización del comercio en Santiago (1880-1930). Santiago, Ediciones UC, 2011.

Faba, Paulina. "Agencias inesperadas: la museificación del pasado colonial en el Chile del siglo xIX”. Atenea, n 512, 2015, pp. 137-151.

---. "Cultura visual y memoria en el Chile del siglo xix. Redefiniendo el coloniaje a través de su exhibición”. Revista de teoría del arte, n² 24, 2013, pp. 13-33.

Fernández, Ricardo. El lujo de las santiaguinas, o el galeteo chileno. Santiago, Imprenta Victoria, 1884. 
Getty Research Institute. Tesauro de Arte y Arquitectura, http://www.aatespanol.cl/ Hellman, Mimi. "Histoires d'objets : arts décoratifs et culture matérielle au xvine siècle”. Perspective, vol. 1, 2011, http://perspective.revues.org/1009

Lander, María Fernanda. "El Manual de urbanidad y buenas maneras, de Manuel Antonio Carreño: reglas para la reconstrucción del ciudadano ideal”. Arizona Journal of Hispanic Cultural Studies, vol. 6, 2002, pp. 83-96.

Letelier, Ambrosio. Reseña descriptiva de la Exposición Internacional de Chile en 1875. Santiago, Imprenta Franklin, 1875.

Mac-Iver, Enrique. Discurso sobre la crisis moral de la República. Santiago, Imprenta moderna, 1900.

Malosetti, Laura. “¿Verdad o belleza? Pintura, fotografía, memoria, historia”. Revista de Crítica Cultural, vol. 4, n² 2, 2009, pp. 111-123.

Metzeltin, Miguel. "La construcción discursiva de la república de Chile". Boletín de Filología, vol. 46, n 1, 2011, pp. 239-253.

Murillo, Juan David. "De lo natural y lo nacional. Representaciones de la naturaleza explotable en la Exposición Internacional de Chile de 1875”. Historia, vol. 48, $\mathrm{n}^{\circ} 1,2015$, pp. 245-276.

Nazer, Ricardo. José Tomás Urmeneta: un empresario del siglo XIX. Santiago: DIBAM y Centro de Investigación Diego Barros Arana, 1994. Impreso.

Perrot, Philippe. Le luxe. Une richesse entre faste et confort XVIII-XIXème siècle. Paris: Seuil, 1995.

Ponce, Pilar y Arrigo Amadori. "Historiografía sobre élites en la América Hispana: 1992-2005”. Nuevo Mundo Mundos Nuevos, 2008, http://nuevomundo.revues. $\operatorname{org} / 38773$

Programa y reglamento de la Exposición Internacional de Chile de 1875, Santiago, 14 de junio de 1873.

Robles, Claudio. "Modernización agraria en el Chile del siglo xix. Los 'hacendados progresistas' y la Exposición Nacional de Agricultura de 1869”. Relics and Selves: Iconographies of the National in Argentina, Brazil and Chile (1880-1890). London, 2000, www.bbk.ac.uk/ibamuseum/texts/Robles01.htm

Roco, Roque. Alrededor de la exposición. Apuntes críticos y descriptivos publicados en el Estandarte Católico. Santiago, Imprenta de El Estandarte Católico, 1875.

Sanhueza, Carlos. "El Museo Nacional de Chile: un espacio local desde una red transnacional (1853-1897)". El carrusel atlántico. Memorias y sensibilidades (1500-1950). Eds. Oscar Álvarez, Alberto Angulo y Alejandro Cardoso. Caracas, Universidad del País Vasco/Editorial Nuevos Aires, 2014, pp. 189-217.

---. "En busca de un lugar en el mundo: viajeros latinoamericanos en la Europa del siglo xix". Estudos Ibero-Americanos, vol. 32, n² 2, 2007, pp. 51-75.

Schell, Patience. "Museos, exposiciones y la muestra de lo chileno en el siglo XIx". Nación y nacionalismo en Chile. Siglo XIX. Vol. 1. Santiago, Ediciones Centro de Estudios Bicentenario, 2009, pp. 85-116. 
Soaje, Raquel. "De Marco Tulio Cicerón a Manuel Antonio Carreño: Un estudio sobre los ideales de vida de las élites en tres momentos de la historia”. Atenea, $\mathrm{n}^{\circ}$ 511, 2015, pp. 189-205.

Soto, Jorge. Historia de la imprenta en Chile, desde el siglo XVIII al XXI, tomo 1. Santiago, Editorial Árbol Azul, 2009.

Stabili, María Rosaria. El sentimiento aristocrático: élites chilenas frente al espejo (18601960). Santiago, Centro de Investigaciones Diego Barros Arana, 2003.

Stuven, Ana María. La seducción de un orden. Las elites y la construcción de Chile en las polémicas culturales y políticas del siglo XIX. Santiago, Ediciones Universidad Católica de Chile, 2000.

Subercaseaux, Ramón. Memorias de ochenta años. Santiago, Imprenta y Litografía Barcelona, 1908.

Subercaseaux, Ramón. Memorias de ochenta años. Santiago, Imprenta y Litografía Barcelona, 1908.

Toro, Pablo. "Dimensiones de la confección de una juventud virtuosa: manuales de urbanidad en Chile (c. 1840-c. 1900)”. Universum, vol. 27, nº 1, 2012, pp. 191-205.

Vizcaíno, Marcelo (con la colaboración de Inés Arribas y Solène Bergot). Ricardo Larraín Bravo (1879-1945). Obra arquitectónica. Santiago, Ediciones Universidad Diego Portales, 2010.

Wasserman, Fabio. “'Las prendas jeniales de nuestra sociedad': representaciones del pasado e identidad nacional en el discurso de las elites político-letradas chilenas (1840-1860)”. Iberoamericana, vol. III, n 9, 2003, pp. 7-26.

Willumsen, María Rosario. “Una colección europea, con impronta francesa: la presencia europea en el arte en Chile a partir de la colección Cousiño Goyenechea. Segunda mitad del siglo XIX”. El sistema de las artes. VII Jornadas de Historia del Arte, En El Sistema de las Artes. VII Jornadas de Historia del Arte. Ed. Angela Brandao et al. Santiago, Museo Histórico Nacional, 2014, pp. 139-147.

Yaeger, Gertrude M. "Sobrellevar el pasado español. Liberalismo latinoamericano y la carga de la historia colonial en el siglo xIx: el caso chileno". Nación y nacionalismo en Chile. Siglo XIX. Vol. 1. Santiago, Ediciones Centro de Estudios Bicentenario, 2009, pp. 117-136.

Enviado: 14 noviembre 2017

Aceptado: 20 junio 2018 